\title{
Oxygen tension in the oviduct and uterus of rhesus monkeys, hamsters and rabbits
}

\author{
B. Fischer ${ }^{1 *}$ and B. D. Bavister ${ }^{2}$ \\ ${ }^{1,2}$ Department of Animal Health and Biomedical Sciences, University of Wisconsin-Madison, \\ Madison, WI 53706, USA; and ${ }^{2}$ Wisconsin Regional Primate Research Center, University of \\ Wisconsin-Madison, Madison, WI 53715, USA
}

\begin{abstract}
Oxygen tension was measured using flexible polarographic microelectrodes within the oviductal and uterine lumen in rhesus monkeys $(n=9)$, golden hamsters $(n=21)$ and rabbits $(n=6)$, during the reproductive cycle (monkey), during oestrus and pseudopregnancy (hamsters, rabbits) and during pregnancy (hamsters). In general, oxygen tensions in each species were much less than half of atmospheric $\mathrm{O}_{2}$, ranging from high values of about $60 \mathrm{~mm} \mathrm{Hg}\left(8.7 \% \mathrm{O}_{2}\right)$ in the rabbit oviduct, rabbit and hamster uterus, to as low as $11 \mathrm{~mm} \mathrm{Hg}$ $\left(1.5 \% \mathrm{O}_{2}\right)$ in the monkey uterus. Oxygen tensions did not vary significantly between left and right sides of the reproductive tracts (all species), nor between pregnant and pseudopregnant states nor between oviduct and uterus (hamsters). Differences owing to reproductive stage were found in the monkey oviduct, hamster oviduct and uterus, and rabbit uterus. Oxygen tensions were consistently very low (11-14 mm Hg) in the monkey uterus throughout the menstrual cycle. In hamsters and rabbits, intrauterine $\mathrm{O}_{2}$ decreased significantly at about the normal time of blastocyst formation and implantation, to $37 \mathrm{~mm} \mathrm{Hg}\left(5.3 \% \mathrm{O}_{2}\right)$ and $24 \mathrm{~mm} \mathrm{Hg}$ $\left(3.5 \% \mathrm{O}_{2}\right)$, respectively. This study indicates that embryos develop in vivo under low oxygen concentrations, especially during the peri-implantation period. The data have implications for investigations of embyro metabolism and for improving embryo development in vitro.
\end{abstract}

\section{Introduction}

Availability of accurate data on the intraluminal oxygen tension within the mammalian female genital tract has attracted increasing attention during recent years, for two reasons. First, it has become apparent from in vitro studies that, depending on species and stage, preimplantation embryos vary widely in their metabolic characteristics, including substrate uptake and utilization, and oxygen consumption. Because we may expect that metabolism and viability are strongly influenced by the oxygen tension to which embryos are exposed, as in somatic cells (Cooper et al., 1958; Packer and Fuehr, 1977; Knighton et al., 1983; Balin et al., 1984), the question is raised: what is the oxygen tension under which preimplantation embryos develop in vivo? Second, in vitro production of embryos from a wide variety of species is becoming increasingly important, for economic as well as for scientific reasons. Although much progress has been made during the last two decades in the ability to support embryonic development in vitro, the viability of cultured embryos is still clearly inferior to that of embryos grown in vivo, irrespective of the species involved (see Biggers, 1987; Fischer, 1987; Kane, 1987; Boatman, 1987; Carney and Foote, 1990; Winston et al., 1991). In vitro culture conditions deviate from the in vivo situation in many respects, but one of the critical

*Current address: Department of Anatomy and Reproductive Biology, RWTH Aachen, Klinikum Pauweisstraße, HD-5207 Aachen, Germany.

Received 14 April 1993. factors appears to be the oxygen concentration in which embryos grow in vitro. Oxygen is toxic to many types of cell at atmospheric levels, probably owing to formation of free oxygen radicals. Several studies have reported improved embryo development in culture using oxygen concentrations much lower than that found in air, which is approximately $21 \%$. These studies examined embryos from mice (Auerbach and Brinster, 1968; Whitten, 1971; Quinn and Harlow, 1978; Pabon et al., 1989; Umaoka et al., 1992), cattle (Wright et al., 1976; Thompson et al., 1990), sheep (Tervit et al., 1972; Thompson et al., 1990), rabbits (Daniel, 1968; Li and Foote, 1993; Lindenau and Fischer, in press) and hamsters (McKiernan and Bavister, 1990). Oxygen concentrations used in these studies were usually selected empirically, for example $1-10 \% \mathrm{O}_{2}$.

Physiological data from measurements of oxygen tension in vivo are needed to provide conditions closely resembling those found naturally. Although there are several such reports (Bishop, 1956; Mastroianni and Jones, 1965; Mitchell and Yochim, 1968a, b; Maas et al., 1976; Garris and Mitchell, 1979; Hammer et al., 1981; Kaufman and Mitchell, 1990), within each study, the data are limited to the oviduct or the uterus and to only one species, making general conclusions difficult to reach. Furthermore, no data on oxygen tension are available for rodent oviducts or for the primate uterus, nor any measurements made during pregnancy or pseudopregnancy, which are of special interest for studies of embryo development in vitro. More extensive data collected in a single study could help resolve the Downloaded from Bioscientifica.com at 04/26/2023 09:32:12AM 
similarities and differences within and between species, and serve as a valuable reference for in vitro techniques. We therefore measured the intraluminal oxygen tension in vivo within the oviduct and uterus in a primate (rhesus monkey), a rodent (golden hamster) and the rabbit; embryos from each of these species have been used to study development in vitro. Measurements were made during different reproductive phases: during the follicular-luteal cycle (monkey), during oestrus and pseudopregnancy (hamster, rabbit), and during pregnancy (hamster). Preliminary results from this study were reported by Bavister and Fischer (1991).

\section{Materials and Methods}

\section{Measurement of oxygen tension}

Oxygen tension was measured with flexible polarographic microelectrodes (Innovative Sensors Inc, (ISI) Anaheim, CA) designed for continuous intravascular recording of in vivo $P_{\mathrm{O}_{2}}$ in human clinical monitoring. The sensor readings, according to the manufacturer, are not affected by changes in solution viscosity and only $\pm 0.5 \%$ by differences in $\mathrm{pH}$. The readings are, however, influenced by temperature changes. Measurements on hamsters and rabbits were made with the animals maintained at $37^{\circ} \mathrm{C}$ within an 'Isolette' infant incubator (model C-86, AirShields Inc., Hatboro, PA) to avoid hypothermic effects of anaesthesia. Oxygen tension measurements on rhesus monkeys were performed at room temperature (approximately $22^{\circ} \mathrm{C}$ ). Ketamine anaesthesia, used for uterine oxygen measurements, does not depress core temperature, which was determined using a rectal thermometer to be $37.4 \pm 0.2^{\circ} \mathrm{C}$ (mean \pm SEM for nine female monkeys at three stages of the menstrual cycle). Halothane-oxygen anaesthesia, used for oviductal oxygen measurements, induces slight hypothermia; core body temperature recordings were therefore made during anaesthesia to approximate the temperature of the reproductive tract. Temperatures were taken at 30 and $60 \mathrm{~min}$ after the onset of anaesthesia, corresponding to the period of oviductal oxygen probe measurements. During this $60 \mathrm{~min}$, the halothaneoxygen mixture depressed core temperature $2.1 \pm 0.2^{\circ} \mathrm{C}(n=9$ animals). Accordingly, oxygen probe values were corrected $(\times 1.03)$ for the reduced temperature that occurred during the oxygen measurements.

Electrodes were connected to a potentiometric oxygen analyser with two channels for simultaneous recording (ISI). The bipolar sensor was equipped with a silver anode and cathode and covered with a hydrophilic membrane. The electrodes had an outer diameter of $0.6-0.7 \mathrm{~mm}$, and could pass through an 18-gauge hypodermic needle. Analyser and electrodes were equilibrated for approximately $\mathrm{I} \mathrm{h}$ before use by placing them in a reference bath consisting of a $250 \mathrm{ml}$ glass beaker filled with $157 \mathrm{mM} \mathrm{NaCl}$ held in a water bath at $38^{\circ} \mathrm{C}$. The $\mathrm{NaCl}$ solution was constantly bubbled with room air to saturate it with $\mathrm{O}_{2}$. After equilibration, the electrodes were calibrated by adjusting the oxygen analyser output reading to $149 \mathrm{~mm} \mathrm{Hg}$; this is the $\mathrm{P}_{\mathrm{O}_{2}}$ of saline solution under standard atmospheric pressure at $38^{\circ} \mathrm{C}$ (corrected for water vapour pressure), which corresponds to $20.9 \% \mathrm{O}_{2}$. Only electrodes giving stable reference bath readings were used for $\mathrm{O}_{2}$ measurements. Measurements were corrected for the barometric pressure prevailing at the altitude of the laboratory.

Measurements of oxygen tension within the oviduct and uterus were taken after 1-2 min of equilibration within the organs. Where appropriate, ovulation and the presence of corpora lutea were ascertained before oxygen tension measurements were made. While making measurements, occlusion of the tip of the electrode within the organs by oviductal or uterine tissue was carefully avoided. After taking a reading, the electrode was briefly rinsed in $\mathrm{NaCl}$ solution containing a small amount of detergent (Liqui-Nox: Alconox Inc., New York, NY) to remove biological fluids, and then replaced in the reference bath. Oxygen tension readings were accepted as valid only if the reference bath reading after retraction from the organ and following equilibration for approximately $2 \mathrm{~min}$ in the reference bath did not deviate by $10 \%$ from the calibrated value of $149 \mathrm{~mm} \mathrm{Hg}$.

\section{Animals}

Rhesus monkeys (Macaca mulatta). Nine naturally cyclic females were used, between 5.5 and 19 years of age (mean $12 \pm 2$ SEM), from the colony of the Wisconsin Regional Primate Research Center. Time of ovulation was estimated by sex skin breakdown, which occurs in $>80 \%$ of the females approximately 1-2 days after ovulation (see Boatman, 1987). For oviduct $\mathrm{O}_{2}$ measurements, the animals were initially anaesthesized with $15 \mathrm{mg} \mathrm{kg}^{-1}$ body weight with ketamine $\mathrm{HCl}$ (Ketaset: Aveco Co. Inc., Fort Dodge, IA) and 0.4-0.6 mg xylazine $\mathrm{kg}^{-1}$ (Rompun, Miles Laboratories, Shawnee, KS), together with $100 \mu \mathrm{g}$ atropine, all injected i.m. Anaesthesia was maintained by inhalation of $1-2 \%$ halothane in oxygen. Oxygen electrodes were introduced into the oviducts using a modification of our laparoscopic embryo transfer procedure. The abdomen of the animal was insufflated with compressed air $(7-8 \mathrm{~mm} \mathrm{Hg}$ pressure) and a laparoscope was inserted to view the oviducts and ovaries. A curved, blunt-ended 19-gauge needle was passed through the body wall and its tip was inserted through the fimbrial ostium to lie approximately $5 \mathrm{~mm}$ inside the ampulla. An oxygen electrode was threaded through this cannula until its tip projected $3-5 \mathrm{~mm}$ beyond the end of the cannula, as indicated by a calibration mark made on the electrode. Possible distortion of the oviductal oxygen tension measurements by the oxygen used for anaesthesia was examined by repeating oxygen tension measurements after withdrawing the halothane-oxygen anaesthesia mixture for a few minutes. The intra-oviductal $\mathrm{O}_{2}$ readings obtained did not change noticeably. Bilateral oviductal $\mathrm{O}_{2}$ measurements were made during a single operation in each of eight monkeys; in the ninth animal, one of the oviducts could not be cannulated and so this was accomplished during a subsequent operation.

For uterine oxygen tension measurements, animals were lightly sedated with ketamine and held in a prostrate position. Oxygen electrodes were inserted non-surgically into the uterine cavity through the cervix using a modification of the embryo flushing procedure routinely used at the Wisconsin Primate Center (Goodeaux et al., 1990). After removing excess cervical mucus by suction, a blunt-ended 18-gauge steel hypodermic needle was threaded carefully through the twisting Downloaded from Bioscientifica.com at 04/26/2023 09:32:12AM 
cervical canal until its tip lay just beyond the internal os, as detected by rectal palpation. The electrode was then passed through this cannula until its tip lay approximately $5 \mathrm{~mm}$ beyond the end of the cannula. Readings were taken as described for oviducts.

In each of six animals, both oviductal and uterine $\mathrm{O}_{2}$ measurements were made at the same cycle stage, that is midfollicular (cycle day 6 or 7), early post-ovulatory (days 14-16) or mid-luteal (days 18-21), although for practical reasons the uterine measurements were made during a later cycle. In the other three monkeys used for oviductal $\mathrm{O}_{2}$ measurements, it was not possible to pass a cannula through the cervix; three new animals were substituted to provide the uterine $\mathrm{O}_{2}$ values (one mid-follicular, two early post-ovulatory).

Rabbits. Sexually mature New Zealand White rabbits ( $\geq 4$ months of age) were either untreated (oestrus; $n=2$ ) or treated with 75 i.u. hCG (Sigma Chemical Co., St Louis, MO) to induce ovulation and pseudopregnancy $(n=4)$. Sedation was attained with $10 \mathrm{mg}$ ketamine $\mathrm{HCl} \mathrm{kg}{ }^{-1}$ and $3 \mathrm{mg}$ xylazine $\mathrm{kg}^{-1}$, both i.m. Fifteen minutes later, full anaesthesia was induced by stepwise intravenous injections of ketamine-xylazine $(2 \mathrm{mg}$ and $0.6 \mathrm{mg}$, respectively, per step). The abdomen was opened through a mid-line incision. An electrode was inserted through the fimbria until its tip lay $1-2 \mathrm{~cm}$ deep into the ampulla; oviductal $\mathrm{O}_{2}$ readings were then taken. Uterine readings were taken in the same animal during the same operation. The electrode was placed $2-3 \mathrm{~cm}$ into the uterine lumen after puncturing the uterine wall with an 18-gauge hypodermic needle. The tip of the electrode was freely movable in the lumen. Care was taken to avoid bleeding and to prevent drying of organs during manipulations. The organs were repositioned into the abdominal cavity while the measurements were being made. Animals were killed without recovery from the anaesthetic when measurements were completed with an overdose of pentobarbital.

Golden hamsters. Regularly cyclic golden hamsters (bred inhouse) were used for this study. Oxygen tension measurements in oestrous females were taken on the day on which mating would normally have taken place during the evening, i.e. on day 4 of the cycle (Orsini, 1961). Other females were mated with fertile or with vasectomized males to induce pregnancy and pseudopregnancy, respectively. Matings were confirmed by the presence of vaginal plugs the next morning. Measurements were performed on each day of pregnancy or pseudopregnancy (in different animals) from the day after mating (day 1 ) each day to day 5 and finally on day 8 . The hamsters were anaesthetized with sodium pentobarbital (Nembutal, $75 \mathrm{mg} \mathrm{kg}^{-1}$ ). Bilateral dorsal incisions were made about $2 \mathrm{~cm}$ lateral to the vertebral column and the upper third of each uterine horn together with the oviduct and ovary were pulled out (see Farrell and Bavister, 1984; Seshagiri and Bavister, 1990). For insertion of the electrode into the oviducts, the procedure described by Farrell and Bavister (1984) for embryo transfer was followed, in which the fimbriae are externalized through a puncture made in the ovarian bursal membrane. Insertion of the electrode was performed using a dissecting microscope inside the Isolette incubator. After insertion of the electrode until its tip lay several millimetres into the ampulla of the oviduct, it was secured in place by tying a ligature (no. 5 braided silk thread) around the fimbria. Bleeding and drying of the organs was avoided by frequently wetting them with $0.9 \% \mathrm{NaCl}$ solution.

For uterine measurements, a puncture was made with a hypodermic needle just below the uterotubal junction, and the electrode was passed through this hole into the lumen until its tip lay about $1 \mathrm{~cm}$ distal to the puncture site. For both oviductal and uterine measurements, which were made in the same animal, the organs with electrodes in place were carefully replaced inside the body cavity while the readings were being made. Twenty-one females were studied, but in one case, only uterine readings could be taken. Animals were killed without recovery from the anaesthetic when measurements were completed with an overdose of pentobarbital.

\section{Data analysis}

For each species, data for left and right oviducts were compared (randomized block ANOVA), and the average of the two measurements was used for subsequent analyses. For each species, differences between oviductal and uterine oxygen measurements were tested using analysis of variance with subject blocks. For each species, effects of stage of cycle or pregnancy/pseudopregnancy (pregnant and pseudopregnant values were pooled for hamsters because no significant differences were found) were analysed for each organ (oviduct or uterus). Multiple comparisons were made by a protected Fisher's least significant difference test; $P<0.05$ was considered to represent statistically significant differences.

\section{Results}

In rhesus monkeys, oviductal oxygen tensions on the ovulatory and non-ovulatory sides were not significantly different $(55 \pm 6 \mathrm{~mm} \mathrm{Hg}$ (mean $\pm \mathrm{SEM}$ ) and $53 \pm 5 \mathrm{~mm} \mathrm{Hg}$, respectively, $n=7$ for each side); data for left and right sides were therefore pooled for analysis. Mean oxygen tension readings in the oviducts (all cycle stages) were higher than those for the uterus (Fig. 1a). Oxygen tension in the oviducts was lower during the mid-follicular phase of the cycle (mean $35 \pm 5 \mathrm{~mm} \mathrm{Hg}$ ) than at either early post-ovulatory or mid-luteal phases $(57 \pm 5$ and $61 \pm 5 \mathrm{~mm} \mathrm{Hg}$, respectively) (Fig. 1b). However, oxygen tension in the uterus was consistently very low (mean $13 \pm 2 \mathrm{~mm} \mathrm{Hg}$ ) throughout the cycle and no cycle differences were observed (Fig. 1c).

In hamsters, there was no difference in oxygen tension between left and right oviducts $(41 \pm 3 \mathrm{~mm} \mathrm{Hg}, n=19$ and $43 \pm 3 \mathrm{~mm} \mathrm{Hg}, n=17$, respectively), between left and right uterine homs $(42 \pm 3 \mathrm{~mm} \mathrm{Hg}, n=21$ and $41 \pm 3 \mathrm{~mm} \mathrm{Hg}$, $n=19$, respectively), or between pregnant and pseudopregnant females (day 2-day 8 only) $(46 \pm 2 \mathrm{~mm} \mathrm{Hg}, n=13$ and $40 \pm 2 \mathrm{~mm} \mathrm{Hg}, n=13$, respectively, for oviductal readings and $41 \pm 3, n=13$ and $44 \pm 3, n=16$, respectively, for uterine readings). Accordingly, data were combined within main categories (oviducts, uteri) for analysis of differences between cyclic (day 0 ) and pregnant/pseudopregnant $(\mathrm{P} / \mathrm{P})$ phases. There was high variability among animals for day 0 measurements, both for oviductal (mean $45 \pm 14 \mathrm{~mm} \mathrm{Hg}, n=3$ ) and 

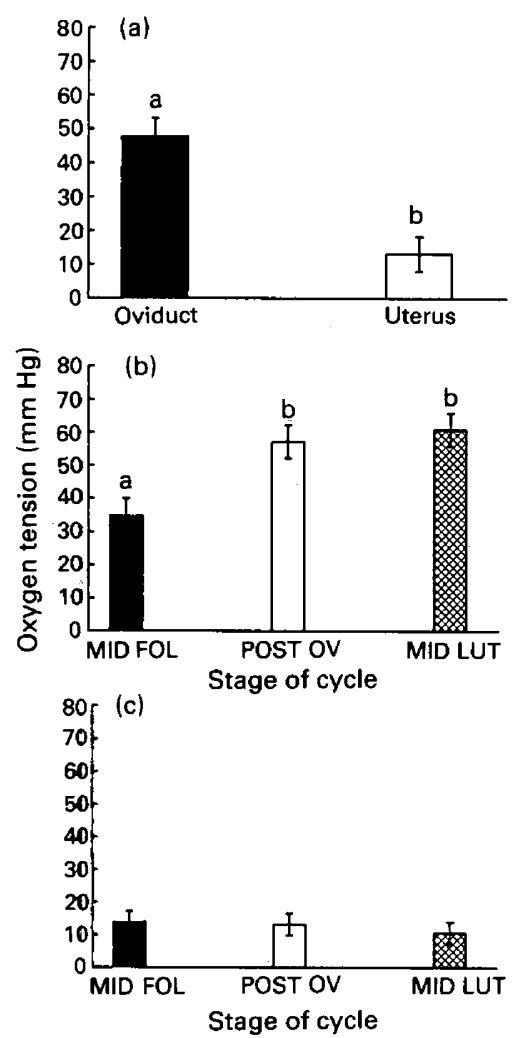

Fig. 1. Oxygen tension measurements in the oviducts and uteri of rhesus monkeys. Data were from nine naturally cyclic animals; all values are ANOVA means \pm SEM. (a) Pooled oxygen tension values for oviduct and for uterus. (b) Oviductal oxygen tension for each cycle stage. (c) Uterine oxygen tension for each cycle stage. Values with different superscripts are significantly different $(P<0.05)$. MID FOL: mid-follicular; POST OV: post-ovulatory; MID LUT: mid-luteal.

uterine ( $37 \pm 7 \mathrm{~mm} \mathrm{Hg}, n=3$ ) oxygen tension. Because of this, the data for day 0 were not statistically analysed with the $\mathrm{P} / \mathrm{P}$ data. Data analysis was performed on P/P from day 1 to day 8 . For both oviductal and uterine $\mathrm{O}_{2}$, there was a rise from day 1 to day 3 (highest levels reached: $53 \pm 3 \mathrm{~mm} \mathrm{Hg}$, and $60 \pm 6 \mathrm{~mm} \mathrm{Hg}$, for oviducts and uteri, respectively), followed by a pronounced drop on day 4 (Fig. 2a,b). There was no difference for either organ among days 4,5 and 8 .

In rabbits, mean oxygen tensions were not different for left and right oviducts ( $48 \pm 4 \mathrm{~mm} \mathrm{Hg}, n=6$ and $55 \pm 7 \mathrm{~mm} \mathrm{Hg}$, $n=6$, respectively) nor for left and right uteri $(43 \pm 7 \mathrm{~mm} \mathrm{Hg}$, $n=6$ and $42 \pm 6 \mathrm{~mm} \mathrm{Hg}, n=6$ respectively); data from the left and right sides were therefore combined within organ categories. Overall mean oxygen tensions were higher in the oviducts than in the uteri ( $53 \pm 3$ and $42 \pm 5 \mathrm{~mm} \mathrm{Hg}$, respectively) (Fig. 3a). Although no differences in mean oviductal oxygen were found across days (day 0, day 1 and day 6 of pseudopregnancy) (Fig. 3b), uterine oxygen tensions were lower on day 6 than on day 1 ( $24 \pm 2$ and $60 \pm 4 \mathrm{~mm} \mathrm{Hg}$, respectively) (Fig. 3c).

\section{Discussion}

In this study, using sensitive polarographic electrodes, we found that in all three species, mean oxygen tension in the

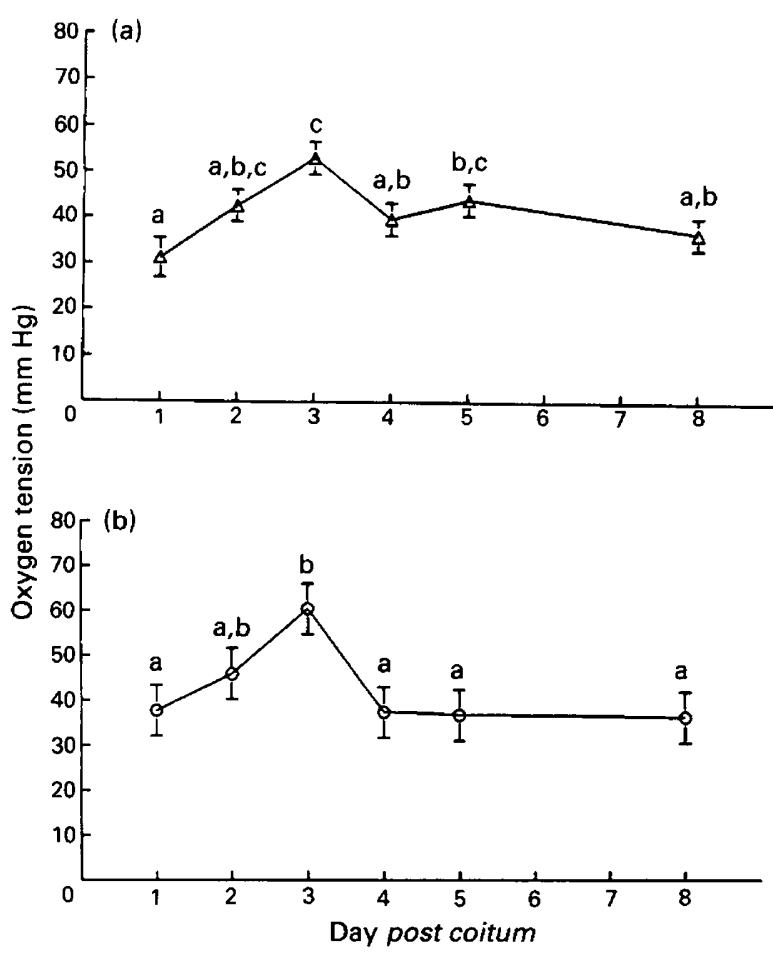

Fig. 2. Oxygen tension measurements in mated hamsters (pregnant and pseudopregnant) for day $I$ to day 8 post coitum. Data from 21 animals; values are ANOVA means and SEM. (a) Oviductal oxygen tension; (b) uterine oxygen tension. Values with different superscripts are significantly different at $P<0.05$.

female reproductive tract was only $40 \%$ or less of atmospheric $\mathrm{O}_{2}$. This confirms previous observations by other investigators. Oxygen tension has been previously measured within the oviduct of rabbits (Bishop, 1956; Mastroianni and Jones, 1965) and rhesus monkeys (Maas et al, 1976), and the uterus of rats (Mitchell and Yochim, 1968a, b; Hammer et al., 1981; Kaufman and Mitchell, 1990), guinea-pigs (Garris and Mitchell, 1979) and hamsters (Kaufman and Mitchell, 1990). However, there are some important procedural differences between the present and earlier studies, and our data and conclusions are at variance with some of the earlier findings. To provide useful comparative data, we measured $\mathrm{O}_{2}$ tension in oviducts and uteri of the same species, which was not done previously, except for a few preliminary observations by Bishop (1956). In addition, we measured oxygen tension in hamsters and rabbits during pregnancy/pseudopregnancy, which is obviously relevant to embryo development; with one possible exception (Bishop, 1956), there are no previous reports in any species on the oxygen tension in the female reproductive tract during these conditions. However, our data are different from the values found by Bishop (1956). Furthermore, our measurements of oxygen tension within the rhesus monkey oviduct are at variance with data from a previous study by Maas et al. (1976). Finally, we also present the first oxygen tension data from the oviducts of a rodent species; this information should be helpful in view of the widespread use of rodent preimplantation embryos for investigation of development of preimplantation embryos in vitro. 

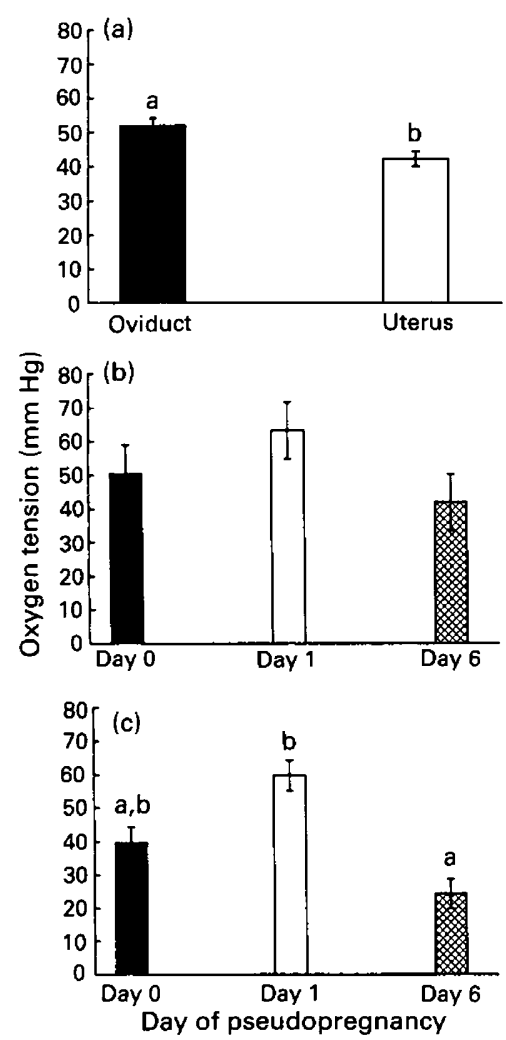

Fig. 3. Oxygen tension measurements in rabbits. Data from six animals; values are ANOVA means \pm SEM. (a) Pooled oxygen tension values for oviduct and uterus. (b) Oviductal oxygen tension for day of oestrus (day 0 ) and day 1 and day 6 of pseudopregnancy. (c) Uterine oxygen tension for day of oestrus (day 0 ) and day 1 and day 6 of pseudopregnancy. Values with different superscripts are significantly different at $P<0.05$.

The study by Maas et al. (1976) in rhesus monkeys appears to be the only other published investigation of oviductal intraluminal oxygen tension in a primate species. These workers reported that the oxygen tension during the follicular phase of the cycle was $<10$ Torr $(\mathrm{mm} \mathrm{Hg})$ or indistinguishable from zero. In addition, they claimed that the oviductal oxygen tension increased following ovulation but only on the ovulatory side; the oxygen tension in the contralateral oviduct (nonovulatory side) remained at $<10 \mathrm{~mm} \mathrm{Hg}$. This differential was attributed tentatively to an increase in oviductal sensitivity to perturbation, so that the presence of the measuring electrode was postulated to stimulate an increase in intraluminal oxygen tension. Extrapolating from this inference, these workers then hypothesized that the electrode tip mimicked the presence of a recently ovulated ovum, which thus may initiate an increased supply of oxygen for its fertilization and embryo development. Although the existence of such a mechanism would be a fascinating example of biological feedback control, our results are not consistent with this scheme. We found that (i) the oxygen tension in the oviduct of rhesus monkeys was not $<10 \mathrm{~mm} \mathrm{Hg}$ during the follicular phase of the cycle but much higher $\left(35 \pm 5 \mathrm{~mm} \mathrm{Hg}\right.$, or $\left.5 \% \mathrm{O}_{2}\right)$, albeit much lower than ambient oxygen levels and lower than in the early post-ovulatory $\left(57 \pm 5 \mathrm{~mm} \mathrm{Hg}, 8.2 \% \mathrm{O}_{2}\right.$ ) or mid-luteal phases $(61 \pm 5 \mathrm{~mm} \mathrm{Hg}$, $8.7 \% \mathrm{O}_{2}$ ); and (ii) there was no difference in oxygen tension between the ovulatory and non-ovulatory oviducts following ovulation ( $55 \pm 6$ and $53 \pm 5 \mathrm{~mm} \mathrm{Hg}$, respectively, approximately $7.8 \% \mathrm{O}_{2}$ ). We do not know the reason for the difference between these two studies, but it may be that the $\mathrm{O}_{2}$ electrodes that we used were more sensitive than those used by Maas et al. (1976), which perhaps could not accurately register low oxygen tensions. Consistent with this idea is the longer latency (1-2 $\mathrm{min}$ ) and equilibration times (2-4 min half-time) for the electrodes used by Maas et al. (1976). In contrast, the ISI electrodes used in our study registered a change in oxygen tension within a few seconds and fully equilibrated to the new value within $15-60 \mathrm{~s}$. Whatever the reason for the differences, we find no evidence to support the idea of an ovum-stimulated change in oxygen tension within the monkey oviduct.

Intraluminal oxygen tension values for rodent oviducts have not been available, possibly because electrodes used in previous studies were not small enough. The ISI electrodes that we used were only $0.6-0.7 \mathrm{~mm}$ in diameter and could be inserted into the hamster oviductal ampulla via the fimbria for a distance of several millimetres, until the first ampullary flexure was encountered. In the study reported here, the profile of daily changes in oxygen tension was not different in the oviduct and uterus. In both organs, there was a pronounced rise in mean oxygen tension on day 3 , that is between the eight-cell-morula stages and blastocyst formation (Bavister et al., 1983). This increase in $\mathrm{O}_{2}$ tension from day 1 to day 3 may be important for embryo metabolism during the early cleavage stages, in both oviduct and uterus. On day 4, there was a marked drop in oxygen tension, again in both organs, corresponding to the time when blastocysts are fully developed and implantation begins. The parallel changes in oxygen tension seen in the oviduct and uterus indicate that a systemic (endocrine) mechanism is responsible, rather than some local action of the developing embryos, as all embryos are in the uterus by day 3 (Bavister et al., 1983). This observation is consistent with the data of Mitchell and Yochim (1968a) showing that uterine oxygen tension in rats is highly influenced by the endocrine status of the animal (oestrogen- or progesterone-dominated). In the hamster uterus at oestrus, we found a mean oxygen tension of $37 \pm 7 \mathrm{~mm} \mathrm{Hg}\left(5.4 \% \mathrm{O}_{2}\right)$, which is similar to the range $(25.7 \pm 4.2)$ reported by Mitchell and Yochim (1968b) for the rat uterus during oestrus.

The mean oxygen tension in the rabbit oviduct was higher than in the uterus, but did not differ statistically over the three days examined. Our data are different from the values reported by Bishop (1956) for the rabbit oviduct. This author found an average of $30 \mathrm{~mm} \mathrm{Hg}$ for $\mathrm{O}_{2}$ under progesterone-dominated conditions; 'progesterone dominance' was not closely defined by this worker, and we do not know if this corresponds to the use of pseudopregnant rabbits, as in our study. Bishop (1956) stated that oviductal oxygen tension was lower in progesteronedominated rabbits than during oestrogen domination (average of 30 and $45 \mathrm{~mm} \mathrm{Hg}$, respectively). We observed a similar trend in oviductal oxygen tensions between oestrus and luteal conditions, but the data were not significantly different; mean values ranged between 42 and $62 \mathrm{~mm} \mathrm{Hg}\left(6-9 \% \mathrm{O}_{2}\right)$ over the 3 days studied. In contrast to the oviductal situation, uterine oxygen tension was significantly lower on day 6 of pseudopregnancy than on day 1 . This period of reduced oxygen tension $\left(24 \mathrm{~mm} \mathrm{Hg}, 3.5 \% \mathrm{O}_{2}\right)$ is near to the time when 
progesterone concentrations reach peak values (see Fischer et al., 1985) and implantation begins.

Several authors have measured intrauterine oxygen tensions following ovariectomy and hormone replacement (for example, Mitchell and Yochim, 1968a; Garris and Mitchell, 1979; Kaufman and Mitchell, 1990). In all three species studied (rats, guineapigs, golden hamsters), there was a sharp increase in uterine $P_{\mathrm{O}_{2}}$ after ovariectomy; however, the reaction after oestrogen replacement was very different in these animals, comprising increased (guinea-pig: Garris and Mitchell, 1979), or drastically decreased (rat: Mitchell and Yochim, 1968a; hamster: Kaufman and Mitchell, 1990) intrauterine oxygen tensions. Although such studies can be very informative about the hormonal regulation of intrauterine oxygen tension, conditions obtained under specific hormone dose regimens in ovariectomized animals may not correspond to the physiological conditions of the luteal phase following mating, that is early pregnancy. Measurement of intraluminal $\mathrm{O}_{2}$ in naturally cycling and $\mathrm{P} / \mathrm{P}$ animals, as in the present study, should provide the closest approximation to normal situations.

In all three species examined in this study, intrauterine oxygen tension was lowest at about the time corresponding to late blastocyst development and implantation (hamster: $37 \mathrm{~mm} \mathrm{Hg}$, $5.3 \% \mathrm{O}_{2}$; rabbit: $24 \mathrm{~mm} \mathrm{Hg}, 3.5 \% \mathrm{O}_{2}$ ) or was consistently low throughout the cycle (monkey: $11-14 \mathrm{~mm} \mathrm{Hg}, 1.5-2.0 \% \mathrm{O}_{2}$ ). This conclusion is at variance with the observation that uterine oxygen tension in guinea-pigs sharply increased in the midluteal phase, that is at about the time of implantation (Garris and Mitchell, 1979). This disparity could be due to species differences, or possibly to a difference in oxygen tension between pregnant and pseudopregnant animals, as used in the present study, and nonpregnant animals used in the work of Garris and Mitchell (1979).

The functional significance of reduced intrauterine oxygen tension at about the time of implantation is unknown, but it may serve to protect the peri-implantation blastocyst from oxygen toxicity, which could be one reason for the inferior development of embryos in culture. Several studies have shown that reduced $\mathrm{O}_{2}(1-10 \%)$ improves development of cultured embryos, in a number of species. In a study with hamster embryos cultured under $20 \% \mathrm{O}_{2}$ or reduced ( 5 or $\left.10 \%\right) \mathrm{O}_{2^{\prime}}$ no detrimental effect of high oxygen on development was observed until the blastocyst stage was reached (McKiernan and Bavister, 1990). A striking effect of $\mathrm{O}_{2}$ toxicity was shown by briefly ( $\mathrm{I}-2 \mathrm{~h}$ ) exposing mouse one-cell embryos to ambient $(20 \%) \mathrm{O}_{2}$ before culturing under $5 \% \mathrm{O}_{2}$; toxicity was not manifested until the morula or blastocyst stages (Pabon et al., 1989), further underscoring the sensitivity of the preimplantation embryo to $\mathrm{O}_{2}$ concentrations. However, several studies have reported that there is no difference in embryo development under reduced $\mathrm{O}_{2}$ (for example, mouse: Legge and Sellens, 1991; cat: Johnston et al., 1991), but this could be due to other rate-limiting factors in the culture environment, masking a detrimental effect of oxygen. Although Daniel (1968) reported that day 5 and day 7 rabbit blastocysts can tolerate a broad range of $\mathrm{O}_{2}$ concentrations in vitro (up to $95 \%$ ), the optimum $\mathrm{O}_{2}$ concentration is much lower as evidenced by $\mathrm{Li}$ and Foote (1993) and Lindenau and Fischer (in press). Rabbit one-cell embryos develop into blastocysts much more frequently ( $\mathrm{Li}$ and Foote, 1993) and blastocysts cultured from the morula stage had a significantly higher cell proliferation (Lindenau and Fischer, in press) when incubated under $1 \%$ or $5 \% \mathrm{O}_{2}$ than in $20 \% \mathrm{O}_{2}$. Taken together, all of these findings indicate that the $\mathrm{O}_{2}$ concentration has to be considered very critically in studies using in vitro embryo culture. Attempts to establish optimal $\mathrm{O}_{2}$ concentrations for in vitro embryo development need to consider possible interrelations with species, stage of embryo development and other culture-associated conditions like composition and volume of the culture media, time of culture, presence or absence of cocultured somatic cells, and oxygen radical formation in vitro. The latter two conditions have attracted considerable attention during recent years. Coculture greatly complicates or obscures investigation of the $\mathrm{O}_{2}$ requirements and tolerances of developing embryos (Bavister, 1993). In vivo, embryos may be protected against free radicals by mechanisms such as oxygen scavengers in oviductal fluid (Legge and Sellens, 1991). However, when mouse embryos were cultured in vitro, the intracellular concentration of $\mathrm{H}_{2} \mathrm{O}_{2}$ was increased (Nasr-Esfahani et al., 1990). The protective effect of radical scavengers such as superoxide dismutase on cultured mouse embryos has been demonstrated by several workers (Iannaccone, 1986; Nasr-Esfahani et al., 1990; Noda et al., 1991; Umaoka et al., 1992).

In vivo measurements of oxygen tension in the oviduct and uterus could help the understanding of the metabolism of embryos at different stages of development. Our data indicate that peri-implantation blastocysts in these three species would be exposed to quite low oxygen tension in vivo, which may play a role in regulating metabolism. Studies on the metabolism of embryos carried out in vitro may be misleading unless physiological oxygen tensions are used. For example, studies performed on blastocysts under oxygen tensions that are near atmospheric values (21\%) may 'drive' the embryos into metabolic behaviour that is abnormal (see Gott et al., 1990). Unfortunately, virtually no information is available on effects of different oxygen tensions on respiration and metabolism of mammalian preimplantation embryos (a rare exception is the study by Khurana and Wales, 1989). This information is critically needed to ascertain whether present concepts about embryo metabolism are influenced by unphysiological oxygen tensions used during the experiments.

The authors are grateful to D. Mohr, S. Eisele and S. Hubbard-Van Stelle for excellent technical assistance, to D. Schramm and M. Tennier for assistance in obtaining some of the rhesus monkey oxygen data, to D. Boatman for data analysis and preparing the figures, and to G. Mathieu for preparing the manuscript. We are indebted to $G$. Bukhamier and S. Rupert of Innovative Sensors, Inc., for generously providing the electrodes and oxymeter used in this study. The authors thank R. Foote and R. Schultz for critical review of the manuscript. This research was supported by the NIH through grants HD 22023 (B. D. Bavister) and RR00167 (Wisconsin Regional Primate Research Center), and by the Max Kade Foundation, Inc., New York (B. Fischer). The work was done as part of the National Cooperative Program on Non-Human In Vitro Fertilization and Preimplantation Embryo Development, supported by NICHD. This is publication no. 32-040 of the WRPRC.

\section{References}

Auerbach S and Brinster RL (1968) Effect of oxygen concentration on the development of two-cell mouse embryos Nature 217 465-466 Downloaded from Bioscientifica.com at 04/26/2023 09:32:12AM 
Balin AK, Fisher AJ and Carter DM (1984) Oxygen modulates growth of human cells at physiologic partial pressures Journal of Experimental Medicine $\mathbf{1 6 0}$ $152-166$

Bavister BD (1993) Co-culture for embryo development: is it really necessary? Human Reproduction 7 1339-1341

Bavister BD and Fischer B (1991) What is the physiological oxygen tension for mammalian pre- and early postimplantation embryos? Joumal of Reproduction and Fertility Abstract Series 7 Abstract 4

Bavister BD, Liebfried ML and Lieberman G (1983) Development of preimplantation embryos of the golden hamster in a defined culture medium Biology of Reproduction 28 235-247

Biggers JD (1987) Pioneering mammalian embryo culture. In The Mammalian Preimplantation Embryo. Regulation of Growth and Differentiation in Vitro, pp 1-22 Ed. BD Bavister. Plenum Press, New York

Bishop DW (1956) Oxygen concentrations in the rabbit genital tract. In Proceedings of the 3rd International Congress of Animal Reproduction Cambridge, pp 53-58

Boatman DE (1987) In vitro growth of non-human primate pre- and periimplantation embryos. In The Mammalian Preimplantation Embryo. Regulation of Growth and Differentiation, pp 273-308 Ed. BD Bavister. Plenum Press, New York

Carney EW and Foote RH (1990) Effects of superovulation, embryo recovery, culture system and embryo transfer on development of rabbit embryos in vivo and in vitro Joumal of Reproduction and Fertility 89 543-551

Cooper PD, Burt AM and Wilson JN (1958) Critical effect of oxygen tension on rate of growth of animal cells in continuous suspended culture Nature $\mathbf{1 8 2}$ $1508-1509$

Daniel JC, Jr (1968) Oxygen concentrations for culture of rabbit blastocysts Journal of Reproduction and Fertility 17 187-190

Farrell PS and Bavister BD (1984) Short-term exposure of two-cell hamster embryos to collection media is detrimental to viability Biology of Reproduction 31 109-114

Fischer B (1987) Development retardation in cultured preimplantation rabbit embryos Journal of Reproduction and Fertility 79 115-123

Fischer B, Winterhager E, Busch LC and Beier HM (1985) Die Pseudogravidität des Kaninchens als reproduktionsbiologisches Modell Fertilität 1 101-109

Garris DR and Mitchell JA (1979) Intrauterine oxygen tension during the estrous cycle in the guinea pig: its relation to uterine blood volume and plasma estrogen and progesterone levels Biology of Reproduction 21 149-159

Goodeaux LL, Anzalone GA, Thibodeaux JK, Menezo Y, Roussel JD and Voelkel SA (1990) Successful nonsurgical collection of Macaca mulatta embryos Theriogenology 34 1159-1167

Gott AL, Hardy K, Winston RML and Leese HJ (1990) Non-invasive measurement of pyruvate and glucose uptake and lactate production by single human preimplantation embryos Human Reproduction 5 104-108

Hammer RE, Goldman H and Mitchell JA (1981) Effects of nicotine on uterine blood flow and intrauterine oxygen tension in the rat Journal of Reproduction and Fertility 63 163-168

lannaccone PM (1986) Microsomal mediated embryo toxicity due to superoxide radicals Teratogenesis, Carcinogenesis and Mutagenesis 6 237-243

Johnston LA, Donoghue AM, O'Brien SJ and Wildt DE (1991) Influence of temperature and gas atmosphere on in vitro fertilization and embryo development in domestic cats Joumal of Reproduction and Fertility 92 377-382

Kane MT (1987) In vitro growth of preimplantation rabbit embryos. In The Mammalian Preimplantation Embryo. Regulation of Growth and Differentiation in Vitro, pp 193-217 Ed. BD Bavister. Plenum Press, New York

Kaufman DL and Mitchell JA (1990) Alterations in intrauterine oxygen tension during the estrous cycle in the rat and hamster and its regulation by ovarian steroid hormones: a comparative study. In Oxygen Transport to Tissue XII pp 745-750 Eds J Piiper, TK Goldstick and M Meyer Plenum Press, New York

Khurana NK and Wales RG (1989) Effects of oxygen concentration on the metabolism of $\left[\mathrm{U}-{ }^{14} \mathrm{C}\right] g$ lucose by mouse morulae and early blastocysts in vitro Reproduction Fertility and Development 1 99-106
Knighton DR, Hunt TK, Scheuenstuhl H, Halliday BJ, Werb Z and Banda M] (1983) Oxygen tension regulates the expression of angiogenesis factor by macrophages Science 221 1283-1285

Legge $\mathbf{M}$ and Sellens MH (1991) Free radical scavengers ameliorate the 2-cell block in mouse embryo culture Human Reproduction 6 867-871

Li J and Foote $\mathbf{R}$ (1993) Culture of rabbit zygotes into blastocysts in protein-free medium with one to twenty percent oxygen Joumal of Reproduction and Fertility 98 163-167

Lindenau A and Fischer B Effect of oxygen concentration in the incubator's gas phase on the development of cultured preimplantation rabbit embryos Theriogenology in press

McKiernan SH and Bavister BD (1990) Environmental variables influencing in vitro development of hamster 2-cell embryos to the blastocyst stage Biology of Reproduction 43 404-413

Maas DHA, Storey BT and Mastroianni L, Jr (1976) Oxygen tension in the oviduct of the rhesus monkey Fertility and Sterility 27 1312-1317

Mastroianni L, Jr and Jones R (1965) Oxygen tension within the rabbit fallopian tube Joumal of Reproduction and Fertility 9 99-102

Mitchell JA and Yochim JA (1968a) Measurement of intrauterine oxygen tension in the rat and its regulation by ovarian steroid hormones Endocrinology $\mathbf{8 3}$ 691-700

Mitchell JA and Yochim JA (1968b) Intrauterine oxygen tension during the estrous cycle in the rat: its relation to uterine respiration and vascular activity Endocrinology 83 701-705

Nasr-Esfahani MH, Aitken JR and Johnson MH (1990) Hydrogen peroxide levels in mouse oocytes and early cleavage stage embryos developed in vitro or in vivo Development 109 501-507

Noda Y, Matsumoto H, Umaoka Y, Tatsumi K, Kishi J and Mori T (1991) Involvement of superoxide radicals in the mouse two-cell block Molecular Reproduction and Development 28 356-360

Orsini MW (1961) The external vaginal phenomena characterizing the stages of the estrous cycle, pregnancy, pseudopregnancy, lactation, and the anestrous hamster, Mesocricetus auratus waterhouse Proceedings of the Animal Care Panel 11 193-206

Pabon JE, Findley WE and Gibbons WE (1989) The toxic effect of short exposures to the atmospheric oxygen concentration on early mouse embryonic development Fertility and Sterility 51 896-900

Packer $\mathbf{L}$ and Fuehr K (1977) Low oxygen concentration extends the lifespan of cultured human diploid cells Nature $267423-425$

Quinn P and Harlow GM (1978) The effect of oxygen on the development of preimplantation mouse embryos in vitro Joumal of Experimental Zoology 206 $73-80$

Seshagiri PB and Bavister BD (1990) Assessment of hamster blastocysts derived from eight-cell embryos cultured in hamster embryo culture medium-2 (HECM-2): cell numbers and viability following embryo transfer Journal of In Vitro Fertilization and Embryo Transfer 7 229-235

Tervit HR, Whittingham DG and Rowson LEA (1972) Successful culture in vitro of sheep and cattle ova Joumal of Reproduction and Fertility 30 493-497

Thompson JGE, Simpson AC, Pugh PA, Donnelly PE and Tervit HR (1990) Effect of oxygen concentration on in-vitro development of preimplantation sheep and cattle embryos Joumal of Reproduction and Fertility 89 573-578

Umaoka Y, Noda Y, Narimoto K and Mori T (1992) Effects of oxygen toxicity on early development of mouse embryos Molecular Reproduction and Development 31 28-33

Whitten WK (1971) Nutrient requirements for the culture of preimplantation embryos in vitro. In Advances in the Biosciences, pp 129-141 Ed. G Raspe. Pergamon Press, New York

Winston NJ, Braude PR, Pickering SJ, George MA, Cant A, Currie J and Johnson MH (1991) The incidence of abnormal morphology and nucleocytoplasmic ratios in 2-, 3- and 5-day human pre-embryos Human Reproduction 6 $17-24$

Wright RW, Jr, Anderson GB, Cupps PT and Drost M (1976) Successful culture in vitro of bovine embryos to the blastocyst state Biology of Reproduction 14 $157-162$ 